\title{
Missões nas fronteiras da América Espanhola: análise comparativa
}

\author{
ROBERT H. JACKSON*
}

Resumo: A coroa espanhola construiu um sistema colonial nas Américas baseado na exploração das populações indígenas. Esse sistema colonial funcionava bem com populações sedentárias que praticavam a agricultura e tinham governos que exerciam o poder central. Nas fronteiras do império, os espanhóis encontravam populaçōes nãosedentárias e, ali, desenvolveram o sistema de missões, nas quais missionários de várias ordens, como os franciscanos e os jesuítas, tentaram mudar a estrutura social e a religião dos neófitos indígenas. Este ensaio oferece uma análise comparativa entre missões no norte do México, durante o período colonial, e no Paraguai.

Abstract: The Spanish Crown constructed a colonial system in the Americas based on the exploitation of the indigenous populations. This colonial system worked well in sedentary populations that practiced agriculture, and that had governments that exercised central control. On the frontiers of the empire, the Spaniards encountered populations that were not sedentary, and developed the mission system where missionaries from various Catholic orders such as the Franciscans and the Jesuits attempted to change the social structure and religion of the indigenous neophytes. This essay offers a comparative analysis of missions in northern Mexico during the colonial period, and in Paraguay.

Palavras-chave: Missões. Paraguai. Nova Espanha.

Key words: Missions. Paraguay. New Spain.

Vários anos atrás fiz um comentário a um historiador jesuíta acerca do "sistema de missões" em vigor no norte do México. O jesuíta respondeu, secamente, que tal sistema não existiu. Contudo, os meus estudos sobre as missões mexicanas incluíram análises comparativas de missões em várias regiões da fronteira norte da Nova Espanha, e esses estudos convenceram-me de que, na realidade, existiu um "sistema de missões", baseado no desenho espanhol para a criação de uma nova sociedade colo-

* Ph. D. pela University of California, Berkeley.

E-mail: academicanarchist@hotmail.com 
nial. Este artigo amplia minha análise anterior, e compara vários aspectos das missões da Baixa e da Alta Califórnia, do Texas e do México, assim como da região Sul Americana do rio da Prata, a chamada "República Jesuíta" do Paraguai.

Para avaliar o desenvolvimento das missões estabelecidas no limbo da América Espanhola, deve-se considerar não só os objetivos políticos espanhóis, mas também quais os benefícios que os povos indígenas acreditavam poder ou não receber ao trocar o seu modo de vida tradicional pela vida de missão. A história das missões não é só a história de missionários, soldados e burocratas, mas é também a história dos povos indígenas que, como agentes autônomos, alteraram o seu próprio destino. Alguns grupos indígenas acreditaram poder beneficiar-se com a vida de missão, dadas as circunstâncias em que se encontravam. Os grupos coahuiltecos do Texas constituem um exemplo de populações indígenas que provavelmente anteviram benefícios com a entrada nas missões do Texas e do nordeste do México. Rodeados pelos comanches e pelos apaches lipan, os coahuiltecos certamente consideraram as missões como refúgios. Considerações semelhantes influenciaram a decisão dos povos guarani da América do Sul de se estabeleceram nas reduções jesuítas, durante o século XVII.

Os guarani eram agricultores sedentários que ocupavam um vasto território no que é o Paraguai moderno e territórios adjacentes. Os jesuítas estabeleceram a primeira redução em 1607, após a decisão da Coroa espanhola de continuar uma política de conquista através dos missionários. Os guarani já tinham tido seis décadas de contato com espanhóis e portugueses, mas esse contato fora baseado no sistema de encomienda e nas rusgas com os bandeirantes de São Paulo, envolvidos em esquemas de escravatura de grande escala. Os caciques guarani provavelmente consideraram os jesuítas como intermediários úteis nas relações com os espanhóis, assim como aliados contra os bandeirantes. Durante a écada de 1630 , os jesuitas organizaram a migração dos guara de áreas vulneráveis aos ataques de bandeirantes para regiões mais seguras, ao mesmo tempo que estabeleceram milícias que operavam nas reduções. Em janeiro de 1641, uma milícia guarani obteve uma vitória notável contra os bandeirantes na batalha de Mborore. ${ }^{1}$ Entre 1637 e 1737, funcionários

1 Herencia Misionera, página da Internet, url:

www.herenciamisionero.com.ar/, capítulo 6. 
da Coroa mobilizaram essas milícias umas cinqüenta vezes para a manutenção da ordem e em campanhas contra os portugueses. ${ }^{2}$ De modo semelhante, os franciscanos das missões do Texas organizaram milícias constituídas por neófitos, embora essas companhias militares fossem estabelecidas só para a defesa das comunidades missionárias, e em muito menor escala que as organizadas entre os guarani.

Como exemplo do envolvimento das milícias guarani em conflitos de caráter internacional podem ser apontados os repetidos ataques dos espanhóis contra a Colônia do Sacramento, um posto fronteiriço português estabelecido em 1680 em território pertencente ao Uruguai moderno. Pouco depois do estabelecimento da Colônia do Sacramento, uma força espanhola, que incluía membros da milícia guarani, capturou o posto, mas um tratado de 1681 devolveu o posto a Portugal. Um quarto de século mais tarde, em 1705, os espanhóis capturaram a Colônia pela segunda vez, com a ajuda de cerca de 4.000 membros da milícia guarani. Em 1731, no final da Guerra da Sucessão Espanhola, a Coroa devolveu o posto da Colônia novamente a Portugal. Do mesmo modo, em 1724, as autoridades locais mobilizaram uma força de 1.000 guarani para expulsar os portugueses de um novo posto erigido na cidade de Montevidéu moderna. Em 1726, a milícia foi de novo mobilizada para ajudar na construção das fortificações da colônia espanhola de San Felipe y Santiago de Montevidéu. ${ }^{3}$

Há semelhanças e diferenças entre as reduções guarani e as missões da Baixa e da Alta Califórnia ou do Texas. A primeira diferença reside no número de indígenas: essas reduções tinham um número muito maior de indivíduos do que as missões localizadas no norte do México, na Califórnia e no Texas. A maior população registrada nas reduções jesuíticas atingiu 128.000 habitantes, em 1733, ou uma média de 4.267 pessoas por redução (Tabela 1, Figura 3).* Essas estatísticas contrastam claramente com as da Califórnia e com as do Texas. Por exemplo, a missão de San Luis Rey, a mais populosa da Califórnia, tinha uma população de 2.869 indivíduos, em $1826 .{ }^{4}$ No entanto, em 1820 , a po-

2 Jesuit Reductions, Catholic Enclyclopedia On Line, página da Internet, url: www.newadvent.org/cathen/.

3 Herencia Misionera, capítulo 11.

* As tabelas e figuras encontram-se no final do texto (N. E.).

4 JACKSON, Robert H. Indian Population Decline: The Missions of Northwestern New Spain, 1687-1840. Albuquerque, 1994, p. 175. 
pulação média da Alta Califórnia era de 1.053, o que permite colocar em contexto a população de San Luis Rey. ${ }^{5}$ As missões da Baixa Califórnia eram menos populosas, embora algumas tivessem populações superiores a 1.500, como foi o caso de Santa Gertrudis e de San Francisco de Borja. Em 1768, a população média das missões da Califórnia era de 477 indivíduos. ${ }^{6}$ As missões do Texas também tiveram populações pequenas, e mesmo a missão de San Jose y San Miguel, a mais populosa das missões da área de San Antonio, tinha 350 neófitos, em 1768. Segundo os registros, a população da missão Rosário, do sul do Texas, flutuou consideravelmente tendo entre 400 a 500 indivíduos durante a década de $1750 .^{7}$

As populações indígenas das missões do norte do México foram instáveis e não viáveis, dado que não se reproduziram por meio de reprodução natural, e dado que as taxas de mortalidade tendiam a ser mais elevadas que as taxas de nascimento. $O$ estudo detalhado da missão de Santa Gertrudis, estabelecida em 1751, na Baixa Califórnia, ilustra amplamente essas características de instabilidade populacional. As fundações da missão de Santa Gertrudis foram estabelecidas por Fernando Konsag, S. J., que estava a cargo da missão de San Ignacio, o local que eventualmente foi escolhido para a missão de Santa Gertrudis, durante a década de 1740 . Os registros de batismo de Santo Ignacio que estão conservados (17431749) mostram que Konsag batizou centenas de índios no território que viria a ser abrangido pela missão de Santa Gertrudis. ${ }^{8}$ Em 1751, quando os jesuítas começaram a manter um registro separado para a nova missão, Konsag já tinha batizado mais de 1.000 pessoas pertencentes à jurisdição de Santa Gertrudis. ${ }^{9}$ Com base no trabalho missionário de Konsag, o primeiro missionário oficialmente a cargo de Santa Gertrudis, Jorge Retz, S. J., completou o batismo das populações não-cristianizadas no prazo de 12 anos..$^{10}$ Em 1762, Ignacio Lizasoain, S. J., Visitador-Geral, apontava que Retz já tinha batizado

\footnotetext{
Tbid., p. 60.
}

Ibid., p. 59.

JACKSON, Robert H. Congregation and Population Change in Mission Communities of Northern New Spain: Cases from the Californias and Texas. New Mexico Historical Review, vol. 69, n. 4, 1994, p. 163-183.

8 JACKSON, Robert H. Demographic Patterns in the Missions of Central Baja California. Journal of California and Great Basin Anthropology, vol. 6, n. 1, 1984, p. 91-112.

9 ASCHMANN, Homer. Central Desert of Baja California: Demography and Ecology. Berkeley and Los Angeles, 1959, p. 166.

10 Ibid., p. 166. 
1.446 nativos, e que o total de batismos atingira 2.059.11 De acordo com esses dados, Jorge Retz completou a evangelização superficial (administração do sacramento do batismo) da população indígena local entre 1751 e 1764 . Como se pode ver pela Figura 2, Retz batizou centenas de indígenas todo ano e durante treze anos. Contudo, e na melhor das hipóteses, o nível de instrução católica teria sido limitado, considerando os problemas logísticos de acesso a uma população vasta e dispersa. O número de neófitos sob influência da missão cresceu durante os primeiros anos da década de 1750 , mas começou a declinar durante meados da década de 1760 , à medida que diminuíam as fontes de novos recrutas e porque as taxas de mortalidade eram consistentemente superiores às taxas de nascimento. ${ }^{12}$

Ao contrário das populações indígenas das missões do norte do México, as populações das reduções do Brasil e do Paraguai não declinaram abruptamente, apresentando períodos de crescimento por reprodução natural. Há vários casos que ilustram essa afirmação. O primeiro a apontar para tal situação é a missão de Santa Ana, estabelecida pela primeira vez em 1633 na região de Tape, hoje a zona central do Estado do Rio Grande do Sul. Em 1638, os jesuítas restabeleceram a missão noutro local, devido aos ataques dos bandeirantes de São Paulo, e mudaram sua localização ainda uma vez mais para o que é hoje o Estado de Misiones, na Argentina. Em 1647, a população de Santa Ana era de 779, e de 5.600 em 1731, 4.778 em 1750, 4.400 em 1767 (imediatamente antes da expulsão dos jesuítas), decaindo, finalmente, para 1.200, em 1801.

O segundo exemplo é constituído por San Ignacio Mini, cuja missão foi primeiramente estabelecida em 1610 em Guairá, mudada para a região do moderno estado de Misiones, em 1631, devido aos ataques dos bandeirantes, e uma vez mais transladada para o seu atual local no Rio Paraná (Estado de Misiones), em 1696. Em 1647, a população de Santo Ignacio era de 1708 . Em 1731, a população atingiu um máximo de 4.300 pessoas, declinando para 2.520 em 1750 , mas aumentando para 3.100 em 1767, para declinar, de novo, depois da expulsão dos jesuítas, para 798 indivíduos, em 1785, e 700 em 1801 (Tabela 2).

11 LIZASOAIN, Ignacio, S. J. Noticia de la Visita General desta Prov[inci]a de Nueva Espana. W. B. Stephens Collection, General Libraries of the University of Texas at Austin.

12 Para informações detalhadas sobre taxas de natalidade e perdas de população nas missões da Baixa Califórnia consultar JACKSON, Robert H. Indian Population Decline: the Missions of Northwestern New Spain, 1687-1840. Albuquerque, 1994. 
As densidades populacionais elevadas registradas nas reduções tornaram essas populações particularmente vulneráveis a doenças de grande contágio, tais como a varíola e o sarampo, ao mesmo tempo que hábitos tradicionais de comércio interno e externo facilitavam a propagação de epidemias. As reduções foram atingidas por surtos epidemiológicos de grande escala, em 1618, $1619,1635,1636,1692,1718,1733,1735,1737,1738-1740$, e 1764. Em 1695, uma epidemia de sarampo matou 600 pessoas da missão Candelária e 2.000 da missão de San Carlos. A década de 1730 foi uma das mais devastadoras. Os relatórios indicam que morreram 18.770 pessoas durante o surto epidêmico de 1733. Em 1735, 18.000 guarani sucumbiram ao sarampo, e a varíola tirou a vida a mais de 30.000 , entre 1738 e $1740 .{ }^{13} \mathrm{O}$ nível populacional das reduções declinou de 141.000 , em 1732 , para 73.910 , em 1740 , mas recuperou-se durante as duas décadas seguintes (Tabela 1).

A recuperação da população guarani sugere uma diferença crucial relativamente às populações indígenas que viviam na Baixa e na Alta Califórnia e no Texas. Os guarani eram uma população de alta fertilidade e de alta mortalidade, semelhante às modernas populações européias. Essas populações registram altas taxas de nascimentos e mortes, resultando num crescimento demográfico de baixo a moderado. As epidemias abrandavam ou estancavam, temporariamente, o crescimento populacional, mas a população se recuperava. $\mathrm{O}$ mesmo não aconteceu com as populações da Califórnia e com as do Texas, que declinaram gradualmente, até o ponto da extinção cultural e da quase extinção biológica.

Uma das diferenças mais significativas nesse contexto foi a organização e o alto nível de comercialização da economia das reduções. Contrariamente ao que se passou na Califórnia e no Texas, os jesuítas do Paraguai e os próprios guarani faziam diferença entre o que chamavam abambae e tupambae. O termo abambae referia-se à terra, ao trabalho e à produção do indivíduo cabeça de família, e era controlado pelos guarani. Tupambae era o trabalho e a produção destinados a Deus, ou, em outras palavras, o trabalho e a produção comunal, que mantinha os jesuítas e o programa missionário das reduções. ${ }^{14}$ Isso não quer dizer que os neófitos indígenas, tanto do Texas quanto da Califórnia, não recebessem parcelas de terra cujo usufruto revertia a favor do indivíduo e de sua família, mas, ao contrário das reduções, a distinção entre produção privada e comunitária não constituiu um princípio organizativo para as missões.

13 Jesuit Reductions, Herencia Misionera, capítulo 10.

14 Herencia Misionera, capítulo 8. 
A agricultura e a criação de gado constituíram a base econômica das reduções, assim como das missões do Texas e da Baixa Califórnia. Contudo, no Paraguai, o nível de exploração desses ramos foi muito maior. Basta considerar que em 1768, durante o período da expulsão dos jesuítas, as reduções possuíam 769.869 cabeças de gado, 138.141 carneiros, e 139.634 cavalos, mulas e burros. Só a redução de Yapeyu contava com mais de 200.000 cabeças de gado, que pastavam numa fazenda de 50 por 30 léguas, ou seja, cerca de $47.000 \mathrm{~km}^{2}$. San Miguel tinha duas fazendas chamadas, respectivamente, Calera de las Huerfanas e Calera de las Vacas, que mediam cerca de $20.000 \mathrm{~km}^{2} .^{15}$ Além de produzir peles para exportação, o gado também era um suplemento alimentar para os guarani residentes nas reduções.

As reduções do Paraguai praticavam especialização econômica e mantinham intercâmbio entre as diferentes reduções. Um grupo de reduções, que incluíam Santo Tome, La Cruz, Yapeyu, San Miguel, San Borja, San Juan Bautista, San Lorenzo, Santo Angel, San Luis e San Nicolas, dedicou-se, particularmente, à criação de gado. Um outro grupo, que incluía Santa Maria da Fe, San Cosme y San Damião, Santiago, Trinidad de Paraná, Jesus de Tavarangue, Santa Rosa, Itapua, San Ignacio Guazu, San Ignacio Mini, Santa Ana e Candelária, especializou-se na produção agrícola. Um outro grupo, cujas reduções estavam localizadas em terras propícias à agricultura e à pecuária dedicou-se a ambas as atividades. Esse grupo incluía as reduções de San Carlos, Santa Maria la Mayor, Aposteles, San Jose e Concepcion. Houve, ainda, um último grupo, cujas atividades econômicas foram mais específicas; esse grupo fornecia erva-mate para o consumo interno das reduções e para exportação, e incluía as reduções de Loreto, San Javier e Corpus Christi. ${ }^{16}$

As terras agrícolas das reduções produziam grande variedade de colheitas para consumo da população guarani e para exportação. Tais colheitas incluíam milho, mandioca e outras raízes indígenas, bem como algum trigo. Outras colheitas de caráter mais comercial incluíam tabaco, índigo, cana-de-açúcar, algodão e ervamate. ${ }^{17}$ A Coroa autorizou os jesuítas a vender erva-mate, em 1645, e, em 1666, a Audiência estipulou um limite para a produção e venda a ser feita pelos jesuítas de 12.000 arrobas (300.000 lbs.)

\footnotetext{
15 Las reducciones misionales del Paraguay. ARBIL, anotaciones de pensamiento y critica 43 página da Internet, url: www.ctv.es/USERS/mmori/(43)redu.htm.

16 Herencia Misionera, capítulo 8.

17 Jesuit Reductions.
} 
anuais. ${ }^{18}$ No final do século XVIII, as reduções produziram 121.000 arrobas (3.025.000 lbs) anuais. O maior número de árvores produtoras de erva-mate existiu na redução de Santa Rosa, seguida por San Cosme y San Damião, com 25.000 árvores. ${ }^{19}$ As reduções também exportavam algodão, trigo, cana-de-açúcar, peles e madeira. ${ }^{20}$ Contudo, foi a exportação de erva-mate que causou maiores problemas entre os jesuítas e os colonos do Paraguai, visto que a concorrência entre ambos levou os colonos a reclamar que os jesuítas excediam as taxas de produção permitidas. Como contraste, as missões da Baixa Califórnia e do Texas não participaram de forma ativa numa economia de mercado; no máximo, os missionários forneciam produtos para as forças militares residentes, como foi o caso de San Jose y San Miguel.

Os missionários tentaram criar estruturas indígenas de controlo social e político, tanto nas reduções quanto nas missões do norte do México. De princípio, vários caciques guarani eram responsáveis por cada grupo residente nas reduções. Contudo, com o passar do tempo, o sistema modificou-se, e os caciques passaram a pertencer a uma espécie de classe privilegiada. Os jesuítas introduziram o sistema espanhol de governação municipal, com um conselho governador (cabildo) eleito anualmente, e com membros responsáveis pelo bom funcionamento da comunidade, particularmente pela administração da justiça. $O$ cacique detentor de mais prestígio ocupava a posição de corregedor. ${ }^{21}$

A prova de que o sistema funcionava razoavelmente bem $\mathrm{e}$ dava voz à população indígena é o fato de que a única revolta significativa nas comunidades missionárias ocorreu em meados da década de 1750 e resultou da transferência das reduções localizadas no Rio Grande do Sul moderno para a jurisdição de Portugal. O Tratado de Madrid, assinado pela Espanha e por Portugal, em 1750, estabeleceu a linha de fronteira entre os territórios espanhóis e portugueses na América de Sul. Uma das provisões do tratado estipulava a transferência do posto fronteiriço português da Colônia do Sacramento, posto esse que tinha sido estabelecido em 1680 , dentro do território do Uruguai moderno, em troca de cerca de 500.000 metros quadrados de território na área ocupada pelo Rio Grande do Sul e pelo norte do Uruguai mo-

18 Herencia Misionera, capítulo. 8.

19 SUSNIK, Branislava. El indio colonial del Paraguay. 2. vols Asunción, 1966, vol. 2, p. 188-189.

20 Herencia Misionera, capítulo 8.

21 Ibid., capítulo 9. 
dernos. O território a ser cedido incluía sete missões localizadas a este do Rio Uruguai (San Miguel, Santo Angel, San Juan Bautista, San Lorenzo Martir, San Francisco de Borja e San Nicolas), assim como também das vastas terras das sete missões de Yapeyu, La Cruz e Santo Tome. A população das sete missões, que totalizava 29.191 pessoas, seria transladada para território espanhol, e os neófitos foram autorizados a levar consigo quaisquer possessões desde que fossem removíveis. O tratado também estipulava que se estas populações não se mudassem dentro do prazo de um ano passariam a ser consideradas portuguesas. Uma disposição secreta do tratado estipulava que tanto as forças espanholas quanto as portuguesas podiam colaborar na expulsão dos neófitos guarani, caso resistissem. As autoridades espanholas confiavam que os missionários jesuítas conseguiriam convencer os guarani a mudar de local, e a Coroa ofereceu 28.000 como compensação. 22

A resistência guarani à implementação dos termos do Tratado de Madrid iniciou em San Juan Bautista, em meados de 1752, com uma declaração dos caciques e dos membros do governo tribal (cabildo). A rebelião alastrou-se rapidamente a outras missões, e os residentes de várias reduções a oeste do rio Uruguai aliaram-se à revolta. Em fevereiro de 1753, a comissão hispano-portuguesa de fronteiras invadiu o território guarani, mas foi forçada a recuar devido à resistência armada dos guarani. Em maio do mesmo ano, os jesuítas residentes nas sete missões demitiram-se. No mês seguinte, o comissário espanhol de fronteiras enviou uma carta aos jesuítas ordenando-lhes que fizessem com que os guarani abandonassem as missões até 15 de agosto. O Artigo n. 8 dessa missiva estipulava que:

Si con sus extraordinarias diligencias, practicadas hasta el dia 15 de agosto proximo, termino ultimo y perentorio, no hubieron podido conseguir que los indios hayan salido en su compania de los pueblos, para establecerse interinamente en los inmediatos ya dichos o en sus nuevos elegidos terrenos, consuman en dicho dia el santisimo Sacramento, y quebrada las copas de los vasos sagrados, para que no pueden servir en usos profanes. Se salgan con solo su brevario de dichos pueblos, y sin dilacion se pongan en camino para esta ciudad [de Buenos Aires] a presentarse a este Gobernador. ${ }^{23}$

22 Ibid., capítulo 11.

23 Referido em Several, Rejane da Silveira. Jesuitas e Guaranis face aos impérios coloniais ibéricos no Rio da Prata. Revista de Historia Regional, vol. 3, n. 1, (verão de) 1998. 
Dessa iniciativa resultou uma série de confrontos militares, que terminaram com a derrota dos rebeldes, em 1756. Em maio de 1754 , forças espanholas e portuguesas invadiram o território guarani, mas foram forçadas a recuar devido ao mau tempo e à resistência dos guarani. Dois anos mais tarde, em fevereiro de 1756, uma força militar composta de 1.020 espanhóis e portugueses invadiu de novo o território guarani e derrotou os guarani em Caibaté, matando 1.511 guarani e capturando 154. Esse conflito custou à força invasora quatro mortos e 30 feridos. Todavia, antes que os espanhóis e portugueses penetrassem no território, os guarani destruíram as colheitas, mataram o gado, e incendiaram San Miguel, San Luis Gonzaga e San Lorenzo. Os soldados espanhóis evacuaram os guarani para o território a oeste do rio Uruguai. ${ }^{24}$ Mais tarde, a Espanha rescindiu o Tratado de 1750 e Portugal devolveu as sete missões, em 1762 .

A revolta guarani desestabilizou o complexo sistema econômico, dado que as missões que produziam mais gado eram exatamente as localizadas nas zonas fronteiriças do Uruguai. Por outro lado, as forças militares foram obrigadas a atravessar as fazendas das missões que não participavam do conflito, provocando ainda mais confusão. Na realidade, as missões localizadas na zona fronteiriça nunca mais voltaram às condições econômicas e de estabilidade anteriores à revolta. Os edifícios necessitavam de reparações, e a população das sete comunidades nunca mais atingiu os níveis pré-1750. Em 1768, sete anos depois da restauração das sete reduções, a população era de 17.723 indivíduos, ou seja, 12.000 menos que a população registrada em 1750 , e o declínio continuou nas décadas que se seguiram à expulsão dos jesuítas do território espanhol, em 1768 (Tabela 3).

Houve, contudo, outras formas de resistência guarani. Uma delas foi a deserção dos indígenas das reduções, antes e depois da expulsão dos jesuítas, mas particularmente depois da expulsão. Entre 1772 e 1776, por exemplo, o número de fugitivos de Santiago totalizou 750, de Santa Rosa fugiram 329, de San Cosme y San Damião 281, de Santa Maria da Fé 683, e de San Ignacio Guazo $368 .{ }^{25}$ O relatório de 1778 sobre as condições das oito missões (Candelária, San Jose, San Carlos, Apostoles, Concepcion, los Santos Martires, Santa Maria e San Javier) apontava para uma força laboral de 3.677 pessoas, mas também registrava 1.146

24 Herencia Misionera, capitulo 12.

25 Ibid., capítulo 20. 
fugitivos. ${ }^{26} \mathrm{O}$ censo de 1735 relativo a San Ignacio Guasu mostrava uma população nominal de 1.842 pessoas, mas o número de guarani presentes na missão era de $1.385 .{ }^{27}$

Também ocorreram revoltas na Baixa e na Alta Califórnia e no Texas. Alguns exemplos de revoltas armadas incluem a revolta de 1734 dos povos indígenas da região do cabo sul da Baixa Califórnia, que resultou na morte de vários jesuítas, a insurreição de 1779 na missão Rosario, no Texas, e a revolta Chumash de 1824 na Alta Califórnia. Mas, como nas reduções guarani, a forma mais freqüente de resistência foi a fuga. As estruturas de poder indígena nas missões da Califórnia, assim como nas do Texas, eram bem mais fracas que as estruturas das reduções e, em geral, os missionários selecionavam neófitos maleáveis para ocupar posições de chefia no incipiente sistema governamental indígena. Não existe qualquer prova histórica da existência de um conselho formal nas aldeias missionárias. Todavia, o controle que os jesuítas exerceram sobre os agrupamentos militares localizados na Baixa Califórnia teve um caráter único.

Em 1767, o governo espanhol tomou uma iniciativa que alterou radicalmente a situação nas reduções guaranis. Nesse ano, a Coroa ordenou a expulsão dos jesuítas das possessões espanholas na América. Essa expulsão afetou diretamente as reduções guaranis e as missões da Baixa Califórnia, e indiretamente as missões do Texas, dado que ambas sofreram o resultado dos problemas inerentes à necessidade de os franciscanos terem de preencher o vácuo deixado pelos jesuítas. Um resultado imediato da expulsão foi a pilhagem sistemática das propriedades das reduções executada pelos administradores civis encarregados da administração dos bens temporais, graficamente visível no número total de cabeças de gado. Com já foi dito, as reduções possuíam mais de 700.000 cabeças de gado, mas os administradores selecionaram e retiraram gado para benefício próprio. Em 1769, existiam 412.169 cabeças de gado, e em 1788 este número estava reduzido a $243.906 .{ }^{28}$ As reduções continuaram a ser administradas por entidades autônomas, até 1848 , ano em que o governo do Paraguai ordenou a confiscação dos bens que restavam. ${ }^{29}$ Contudo, as reduções, agora denominadas aldeias de índios, tinham sofrido perda de população.

26 Ibid., capítulo 18.

27 Susnik, El Indio Colonial, vol. 2, p. 188-189.

28 WHTTE, Richard. Paraguay's Autonomous Revolution 1810-1840. Albuquerque, 1978, p. 27.

29 WHIGHAM, Thomas. Paraguay's Pueblos de Indios Echoes of a Missionary Past. In: LANGER, Erick e JACKSON, Robert H. (eds.). The New Latin American Mission History. Lincoln, 1995, p. 179. 
Como foi mencionádo anteriormente, as populações das reduções flutuaram devido ao elevado índice de mortalidade causado pelas epidemias. Mas, durante as últimas décadas do século XVIII o declínio populacional deveu-se ao abandono dos neófitos. A Tabela 2 mostra o declínio populacional nas comunidades de Candelária, Itapua e em San Cosme y San Damião, depois de 1767. Um outro fator importante no declínio populacional foi a destruição física de várias das reduções localizadas no território do atual Rio Grande do Sul e da Argentina, causada pelas guerras entre Portugal, a Argentina e o Paraguai, guerras essas que visavam ao controle da Facha Oriente (Uruguai) e áreas contíguas, e que tiveram lugar durante as três primeiras décadas do século XIX.

Em 1801, durante a guerra entre a Espanha e Portugal, uma milícia portuguesa ocupou as sete missões localizadas a leste do rio Uruguai, as mesmas missões que tinham sido devolvidas à Espanha quando do fiasco do Tratado de Madrid e da Guerra Guarani. ${ }^{30}$ Essas missões serviram de base de operações para as invasões portuguesas da região entre os rios Uruguai e Paraná durante as décadas tumultuosas de 1810 e 1820 . As invasões tiveram lugar em 1811, 1812 e em 1817 e 1818. Durante a última invasão, os portugueses saquearam várias das reduções, e nesses conflitos morreram 3.190 pessoas das missões e 360 foram feitas prisioneiras. Uma das mais ferrenhas batalhas ocorreu em abril de 1818, em San Carlos, resultando quase na destruição da igreja e dos edifícios vizinhos. Em 1817, o Paraguai também tentou assumir o controle sobre as missões, e no processo foram saqueadas as comunidades missionárias ao longo da margem leste do rio Paraná, tais como San Ignacio, Santa Ana Loreto e Corpus Christi, entre outras..$^{31}$

Os guarani abandonaram muitas das reduções localizadas na zona de batalha e procuraram refúgio noutros locais ou foram forçados a estabelecer-se noutras zonas. A odisséia de um grupo de guarani residentes nas missões do leste do rio Uruguai ilustra o dilema dos refugiados apanhados pelos conflitos políticos vividos na região. Em 1828, durante a guerra entre a Argentina e o Brasil pela disputa do Uruguai, Fructuoso Rivera saqueou sete das reduções na zona fronteiriça do Uruguai e levou para o Uruguai cerca de 6.000 guarani. Esse grupo guarani estabeleceu-se no rio Paraná, numa aldeia chamada Santa Rosa de la Bella Union. Os refugiados

30 Herencia Misionera, capítulo 21.

31 Ibid., capítulos 26-28. 
permaneceram nesse local cinco anos, mas foram forçados a fugir, na seqüência, de um ataque à aldeia perpetrado pela milícia da facção colorada envolvida com a facção blanca numa guerra civil local. Um grupo de 860 guarani, proveniente das onze reduções, estabeleceu de novo um aldeamento denominado San Borja del Yi, e eventualmente a população desse aldeamento atingiu cerca de 3.500 habitantes. ${ }^{32}$

O final das missões do norte do México foi muito diferente. A expulsão dos jesuítas da Nueva Vizcaya, Sinaloa, Sonora e da Baixa Califórnia não resultou no saque das missões, tal como aconteceu no Paraguai. O governo ordenou a secularização das missões mais antigas, mas noutras áreas, tais como na zona norte de Sonora e na Baixa Califórnia, os franciscanos substituíram os jesuítas. Os dominicanos substituíram os franciscanos na Baixa Califórnia e estabeleceram novas missões durante as últimas décadas do século XVIII. Além disso, em 1769, o governo organizou uma expedição destinada a colonizar a Alta Califórnia, e eventualmente os franciscanos estabeleceram na zona 21 missões novas.

O fim das missões no norte do México resultou, em parte, do drástico declínio das populações indígenas. Por exemplo, no caso do Texas, a pressão exercida pelos colonos teve um papel fundamental na decisão de secularizar a missão de San Antonio de Valero e foram os colonos que tiraram o maior proveito da secularização das missões restantes. As minorias populacionais indígenas que existiam no final do século XVIII foram usadas como justificativa para o reagrupamento e o fechamento das missões. Em 1790, San Antonio de Valero contava com 48 pessoas, e somente 305 indivíduos permaneciam nas outras quatro missões localizadas na área de San Antonio. A diminuta população de San Antonio forneceu aos administradores locais a razão ideal para fechar a missão, e permitiu que as terras pertencentes às outras missões pudessem ser distribuídas entre os colonizadores sem terra. Em 1815, quando o governo decretou a secularização das quatro missões restantes, só existiam 107 neófitos, e apenas uma meia dúzia de famílias de neófitos sobreviveu para receber a maior parte das terras que anteriormente pertenciam às missões. ${ }^{33}$ Como agravante, os administradores civis encarregados de gerir os negócios das missões secularizadas aproveitaram as suas posições para arrebatar as melhores parcelas de terra.

33 Jackson, Congregation and Population Change, p. 174. 
A influência de movimentos como o Iluminismo e o Liberalismo, e as conseqüências de onze anos da Guerra de Independência do México contribuíram para o fechamento das missões do norte do México. O número de missionários, principalmente de nacionalidade espanhola, declinou, obrigando a escolhas difíceis para preencher as vagas de missionários permanentes. Por outro lado, após a independência do México, registrou-se uma crescente animosidade contra os espanhóis, que resultou em decretos de expulsão. Esses decretos não abrangiam os missionários nascidos na Espanha, mas as dificuldades em encontrar missionários suficientes para preencher as vagas continuaram. Após a independência, o sentimento anticlerical produziu críticas que consideravam a missão como um anacronismo colonial, que só atrasava a reintegração do índio na sociedade. Essa perspectiva levou os reformadores liberais a escolherem como alvo o fechamento das missões, logo que ocuparam o poder, no princípio da década de 1830 . A lei de secularização de missões passada em 1833 pelos políticos liberais mexicanos apenas confirmou o estado de decadência da maioria das missões do norte do México. O único sistema missional viável afetado pela lei de 1833 foi o sistema das missões franciscanas da Alta Califórnia, onde o processo de secularização resultou na dispersão das populações indígenas. Como tinha acontecido no Texas e na Baixa Califórnia, foram os colonos os principais beneficiados com a distribuição das terras que tinham pertencido às missões. ${ }^{34}$

\section{Cidades na selva}

Uma das tarefas principais dos missionários era estabelecer comunidades na selva, modeladas no plano espanhol criado para as Américas. Essas cidades deviam ser desenhadas seguindo o plano quadriculado (grid plan), a partir da praça principal. Os jesuítas planejaram as reduções de maneira a incluir uma vasta praça, que, eventualmente, seria dominada por uma igreja imponente, que incluía um claustro que servia de residência para os frades, assim como outros aposentos destinados às atividades da missão. Esse complexo arquitetônico também incluía casas para os neófitos guarani, edifícios destinados a várias atividades

34 Para uma perspectiva generalizada sobre o fim das missões do norte do México consultar Jackson, Robert H. From Savages to Subjects: Missions in the History of the American Southwest. Armonk, New York, 2000, capitulo 6. 
industriais, sistemas de irrigação, uma casa para o conselho da aldeia e um dormitório destinado às mulheres solteiras e viúvas, denominado coty guazu. Antonio Sepp, S. J., e fundador de San Juan Bautista, uma missão localizada no Rio Grande do Sul moderno, descreveu o modo como procedeu à ereção dos edifícios da nova redução:

No aprendí, por cierto, con ningún arquitecto cómo hay que trazar un pueblo. Pero he viajado por tantos países y provincias que me di cuenta de cómo muchas aldeas, ciudades y villas europeas han sido construidas casi sin orden por sus fundadores y cómo sus sucesores las han ampliado sin sistema [...]. Yo quería evitar éstos y otros errores y trazar mi pueblo metódicamente, según las reglas del urbanismo. La primera condición con la cual debía cumplir fue la medición y el amojonamiento de los terrenos para la construcción de las casas con el cordel del agrimensor [...]. En el centro tuve que alinear la plaza, dominada por la iglesia y la casa del párroco. De aquí debían salir todas las calles, siempre equidistantes una de la otra. Una buena distribución en este sentido significaba una ventaja extraordinaria $y$, al mismo tiempo, el mejor adorno para el pueblo. El cura puede, así, viaticar a sus parroquianos de la manera más rápida y cómoda [...]. La plaza era de cuatrocientos pies de ancho y quinientos pies de largo. A ambos lados de la iglesia se elevan, como en un anfiteatro, las casas de los indios, formando filas bien ajustadas [...]. De la plaza salen las cuatro calles principales, construidas en forma de cruz, que miden a lo ancho sesenta metros y a lo largo más de mil, y llevan al campo en todas direcciones. ${ }^{35}$

O desenvolvimento do complexo de edifícios que constituía uma missão atravessou várias fases. Na fase inicial, os jesuítas dirigiam a construção de edifícios temporários, construídos em madeira, com ou sem adobe, ou taipa francesa (construção de barro misturada com pequenos ramos de árvore, ou seja, wattle and $d a u b)$. A segunda fase implicava a construção das estruturas principais do complexo em pedra, com ou sem adobe, e assentes numa base de pedra. Essas estruturas incluíam as casas para a população indígena, oficinas, etc., ao mesmo tempo que a missão mantinha uma igreja temporária. A fase final em várias reduções era marcada pela edificação de uma igreja nova e magnífica construída em pedra. A construção desses templos monumentais ocorreu nas décadas de 1740, 1740 e 1750, décadas de que datam as igrejas de San Ignacio, San Miguel e Candelária, entre outras. A construção da majestosa igreja de Jesus de Tavarangue ini-

Citado em Herencia Misionera, capítulo 15. 
ciou-se no fim da década de 1750 , mas ainda não tinha sido finalizada quando os jesuítas foram expulsos. ${ }^{36}$ Durante as mesmas décadas, os jesuítas da Baixa Califórnia empenharam-se na construção de igrejas novas e imponentes, tais como Loreto, San Francisco Xavier, Mulege, Comondu e Guadalupe.

Os jesuítas deixaram-nos algumas provas escritas das idéias que guiaram o progresso da construção desses complexos, e esses relatórios históricos demonstram a orientação dada ao planejamento das comunidades. Um documento de 1714 da missão de Santa Maria la Fe nota que:

Porque este pueblo esta mal formado, o plantado no tienen ya por donde extenderse bien, si no es a lo largo de suerte que se retiran mucho de la iglesia, y casa del padre las casas que de nuevo es necesario fabricar, de donde ha de haber mucha incomodidad para asistir con los ministerios prontamente, como se debe, a los enfermos y demas gente que hubiese vivir en los retirado. ${ }^{37}$

Um memorial escrito em 1749 e destinado aos jesuítas estacionados em Loreto fornece instruções específicas para a reconstrução das casas dos neófitos. Nele lê-se:

Pongase empeno en conmponer las casas de los indios, y en hacer otras casas nuevas para que todo el pueblo pueda vivir en casas de tejas, con esto se libraria del riesgo de quemarse las casas de paja, que muchos usan. Los pilares de las casas que se hicieren seran de piedra como esta la que ahora se acaba de hacer. ${ }^{38}$

O inventário da missão de Aposteles, preparado em 1768 na altura da expulsão dos jesuítas, faz o seguinte relato do progresso da construção dos edifícios da missão:

Tiene este pueblo al presente setenta y cuatro hileras de casas, y todas estan techadas con tejas. Las viente y dos hileras de ellas, de pared de piedra, y cinco de ellas son con horcones de piedra tambien. ${ }^{39}$

As missões da Califórnia e do Texas seguiram uma seqüência semelhante, embora os complexos missionários do Texas, tais como San Jose y San Miguel, incorporassem um elemento único - estruturas defensivas para proteger as missões dos ataques de grupos nativos, tais como os apaches lipan. A missão era rodeada de uma muralha com bastiões posicionados nos quatro cantos

36 Ibid., capítulo 15.

37 Citado em Ibid., capítulo 14.

38 Citado em Ibid., capítulo 15.

39 Citado em Ibid., capítulo 14. 
da muralha e abastecidos com canhões. As casas da população nativa ficavam no interior das muralhas, e as portas que davam acesso ao exterior do complexo também estavam equipadas com estruturas defensivas. Nenhum outro complexo missionário localizado no norte do México incorporou essas estruturas defensivas. Do mesmo modo que nas outras áreas, as construções temporárias eram feitas de madeira ou de lama barrosa misturada com ramagem (wattle and daub), mas em algumas das missões os missionários chegaram a dirigir construções de pedra ou adobe que tinham um caráter mais permanente.

Os franciscanos da Alta Califórnia deixaram relatos detalhados das fases sucessivas da construção dos complexos missionários. Um sumário da construção da missão La Purisima, estabelecida em 1788, documenta a seqüência de construção. Os franciscanos estabeleceram La Purisima, na primavera de 1788, numa aldeia chumash chamada Salsacupi. Durante os vinte quatro anos de ocupação de Salsacupi, os franciscanos dirigiram a construção de um vasto complexo missionário. Em dezembro de 1812, um forte terremoto, seguido de chuvas torrenciais, causou danos irreparáveis, e, alguns meses depois, os frades mudaram a missão para Los Berros, um local a várias milhas de Salsacupi. ${ }^{40}$ Existem bastantes provas históricas e arqueológicas que documentam em detalhe a seqüência de construção das missões em ambos os locais.

Os missionários franciscanos residentes na missão La Purisima tinham noções generalizadas de técnicas de construção, mas não eram de modo algum arquitetos. À distância, e dado o nível de atividade sísmica na Califórnia, a escolha do local para a missão foi mal feita. Além disso, algumas das estruturas do casco (conjunto de edifícios), especialmente edifícios de vários andares destinados a celeiros e armazenagem, foram particularmente vulneráveis. Em março de 1813, Mariano Payeras, O. F. M., um frade que não tinha estado na missão La Purisima durante a principal fase de construção do casco, comentava que a missão fora construída numa colina que inclinava de sul para norte e que os edifícios tinham soalhos e tetos desnivelados. Os franciscanos fizeram com que os neófitos nivelassem o terreno, mas continuaram a existir desníveis. A missão fora construída numa zona aluvial localizada na base das colinas, uma zona conseqüentemente pouco estável durante terremotos. Quando do terremoto de dezembro de 1812, as construções nas encostas das colinas desmoronaram na direção do

40 ENGELHARDT, Zephyrin O. F. M. Mission La Concepcion Purisima de Maria Santisima. Santa Barbara, 1986. 
declive. ${ }^{41}$ Ponderando os planos para a mudança da missão, Payeras declarou a intenção de construir um complexo de edifícios menor e com prédios mais sólidos e mais baixos. ${ }^{42} \mathrm{O}$ terremoto devastador de 1812 tinha ensinado a Payeras que era preciso construir em escala reduzida e com estruturas mais fortes para resistir aos terremotos. O casco de Salsacupi, construído em larga escala, tinha demonstrado a sua vulnerabilidade a terremotos.

A construção do casco de Salsacupi foi rápida - em treze anos completara-se o vasto quadrado e a igreja. Em 1788, os franciscanos tinham construído várias estruturas temporárias de barro e ramagem (wattle and daub), incluindo uma capela e aposentos para os frades. No ano seguinte, iniciaram a construção de edifícios permanentes em adobe. A primeira estrutura construída em adobe foi a igreja (1789), que viria a ser alargada em 1792.

Durante a década de 1790 , os franciscanos agregaram centenas de chumash à comunidade missionária e, em termos totais, a população cresceu rapidamente. No final de 1789 , quando a primeira igreja de adobe estava quase concluída, 151 chumash viviam na missão, e esse número aumentou para 920 em 1798 , quando os franciscanos iniciaram a construção de uma igreja nova e maior, que levou quatro anos para ser concluída (1798-1802 dedicada em fevereiro de 1803).43 A rápida expansão populacional tinha tornando a igreja pequena demais, mesmo depois do alargamento efetuado em 1792. A arqueóloga Julia Costello calculou que a igreja teria $99,4 \times 54,4 \times 6$ pés. $^{44}$

Relatórios anuais mais recentes indicam que a azáfama de construção continuou, embora sem especificar o uso dos novos edifícios. $\mathrm{O}$ esquema geral das outras missões demonstra que, à parte a igreja, os primeiros edifícios permanentes a serem construídos eram os aposentos dos frades e os dormitórios para as mulheres solteiras e para as raparigas que atingiam a puberdade. ${ }^{45} \mathrm{E}$ provável que durante os primeiros dois anos os franciscanos tivessem continuado a utilizar a residência temporária construída em

41 MARIANO Paye s O. F. M. to Jose Joaquin de Arrillaga, La Purisima, March 11, 1813. In: CUTTE Donald, (trad. e ed.). Writings of Mariano Payeras. Santa Barbara, 1995, p. 69 (de agora em diante citado como WMP).

42 Ibid., p. 69.

43 Jackson, Indian Population Decline, p. 173.

44 Julia Costello. "Mission Vieja de la Purisima CA-SBA-521H: Report on the 1991-1992 Archaeological Investigations". Unpublished report on file with the City of Lompoc Community Development Department, 1993.

45 JACKSON, Robert H, e CASTILLO, Edward. Indians, Franciscans and Spanish Colonization: the Impact of the Mission System on California Indians. Albuquerque, 1995, p. 137-168. 
1788 e que, no início da década de 1790 , ocupassem novos centos, possivelmente construídos nessa década. O relatório anual de 1790 nota a construção de sete quartos, mas não especifica o seu uso, embora seja possível que esses incluíssem novos aposentos para os frades. O relatório de 1797 inclui a construção de uma nova residência para os missionários, provavelmente localizada na parte leste do complexo (Tabela 3).

Os franciscanos também construíram aposentos para pessoal auxiliar. O governo mantinha uma pequena escolta para proteção dos missionários e para controlar os neófitos indígenas. A documentação indica que os franciscanos construíram dois, e possivelmente três, quartéis para esses soldados. O primeiro quartel terá sido erigido em 1791, quando os franciscanos relatam a construção de três edifícios fora do complexo central. O relatório não indica a que eram destinados os edifícios, mas um deles poderia ser o quartel. Três anos mais tarde, em 1794, os missionários mencionam a construção de outro quartel, e em 1798 a construção de um quartel novo e, presumivelmente, maior. É possível que as fundações encontradas ao norte do quadrado principal sejam o que resta do último quartel. Normalmente os franciscanos contratavam um capataz que era também membro da escolta, e o relatório de 1794 refere a construção de uma residência para o capataz. O mesmo relatório indica a construção de um aposento para os visitantes da missão. O terremoto de 1812 também destruiu 100 casas de neófitos construídas em adobe (Tabela 3).

A escala de construção diferiu entre as missões e as reduções do Paraguai: por exemplo, o complexo de Loreto parece abranger 75 hectares. Contudo, a configuração básica no plano quadriculado era a mesma. Além disso, os materiais de construção foram os mesmos (pedra e adobe), assim como certos detalhes de construção, tais como os telhados de telha inclinados, hoje associados às missões da Califórnia e ao estilo arquitetônico que se tornou popular nos Estados Unidos no início da década de 1920. No processo de criar novas comunidades, os missionários do Paraguai e do norte do México incorporaram vários elementos fundamentais. A igreja era o edifício mais imponente da comunidade e era implantada na praça principal simbolizando para os indígenas a grandiosidade da nova religião. O segundo elemento era a conceito de que os neófitos deveriam viver em comunidades de estilo europeu, com edifícios e casas construídas em pedra e de adobe. 


\section{Conclusões}

Embora existam diferenças relativas ao ambiente e à cultura dos povos indígenas, as missões do norte do México e do Paraguai foram indiscutivelmente bastante semelhantes em termos de organização básica e dos objetivos estabelecidos pelo governo espanhol e pelos missionários. Sendo assim, será correto falar de um "sistema missional" que operou durante o período colonial espanhol, tanto na América do Norte quanto na América do Sul.

\section{Anexos}

\section{Tabela 1}

População total das reduções jesuíticas durante anos selecionados

\begin{tabular}{|r|r|r|r|r|c|}
\hline Ano & População & Ano & População & Ano & População \\
\hline 1648 & 30,548 & 1733 & 128,389 & 1750 & 95,089 \\
\hline 1677 & 58,118 & 1737 & 104,473 & 1768 & 88,864 \\
\hline 1702 & 89,500 & 1739 & 81,159 & 1772 & 80,891 \\
\hline 1717 & 121,168 & 1740 & 73,910 & 1784 & 57,949 \\
\hline 1732 & 141,242 & 1743 & 81,355 & 1801 & 45,637 \\
\hline
\end{tabular}

Fonte: "Reductions of Paraguay," Catholic Encyclopedia, Internet File; Whigham, Thomas. "Paraguay's Pueblos de Indios: Echoes of a Missionary Past". In: Langer, Erick e Jackson, Robert H. (eds.). The New Latin American Mission History. Lincoln, 1995, p. 168; Herencia Misionera, Internet site, url: www.herenciamisionero.com.ar/; Maeder, Ernesto. "La poblacion de las misiones de Guaranies (1641-1682). Reubicacion de los pueblos y consecuencias demograficas". Estudos Ibero-Americanos, Porto Alegre, vol. 15 n. 1 (junho de) 1989, p. 49-80; Maeder, Ernesto. "Fuentes Jesuiticas de informacion demografrica misional para los siglos XVII y XVIII". In: Celton, Dora (coord.). Fuentes utiles para lose studios de la poblacion Americana: Simposio del 49. Congreso Internacional de Americanistas, Quito 1997. Quito, 1997, p. 45-57; Cardiff, Guillermo Furlong, S. J. Misiones y sus pueblos de Guaranies. Buenos Aires, 1962, p. 175-179; Hernandez, Pablo, S. J. Organizacion social de las Doctrinas Guaranies de la Compania de Jesus. 2 vols. Barcelona, 1913, vol 2, p. 616617. 
Tabela 2

População total das reduções jesuíticas durante anos selecionados

\begin{tabular}{|c|c|c|c|c|c|c|}
\hline Missāo & $1641 / 43$ & 1647 & 1657 & 1667 & 1676 & 1682 \\
\hline Guasu & 998 & 1150 & 1327 & 1940 & 2326 & 2741 \\
\hline Itapua & 2199 & 1700 & 2292 & 2735 & 3094 & 3288 \\
\hline Candelária & 1490 & 1077 & 1471 & 2363 & 1991 & 1868 \\
\hline S Cosme & 2100 & 1075 & 1376 & & 1210 & 1283 \\
\hline SAna & 850 & 779 & 1024 & 1300 & 1352 & 1415 \\
\hline Loreto & 1476 & 1700 & 1920 & 2089 & 2358 & 2772 \\
\hline S I Mini & 1750 & 1708 & 2171 & 2439 & 2253 & 2441 \\
\hline S Carlos & 2300 & 1701 & 2123 & 2714 & 3633 & 4420 \\
\hline S Jose & 1441 & 1334 & 1268 & & & 2272 \\
\hline Corpus & 1604 & 1300 & 1331 & & & 1350 \\
\hline Aposteles & 1635 & 1144 & 3239 & & 2158 & 3548 \\
\hline S Nicolas & 1803 & 1854 & 3684 & & 2921 & 3548 \\
\hline Concepcion & 3665 & 1469 & 3275 & & 6035 & 7014 \\
\hline S Javier & 1442 & 1300 & 1604 & & 2740 & 3029 \\
\hline La Mayor & 2637 & 2000 & 2776 & & 4378 & 5171 \\
\hline Martires & 1040 & 1186 & 1278 & & 1769 & 1980 \\
\hline S Miguel & 1860 & 1165 & 2101 & & 3830 & 3740 \\
\hline La Cruz & 1300 & 1472 & 1514 & & 2212 & 2251 \\
\hline San Tome & 3000 & 1960 & 3494 & & 5129 & 5243 \\
\hline Yapeyu & 1600 & 1600 & 1828 & & 2100 & 2477 \\
\hline
\end{tabular}

Fontes: As mesmas da Tabela 1. 


\begin{tabular}{|c|c|c|c|c|c|c|c|c|c|c|}
\hline Missāo & 1702 & 1724 & 1731 & 1733 & 1739 & 1740 & 1741 & 1750 & 1756 & 1759 \\
\hline Guasu & 3700 & 3343 & & 1266 & 1964 & 2018 & 2152 & 2251 & 2472 & \\
\hline $\mathrm{LaFe}$ & 2739 & 5463 & & & 2903 & 3086 & 3298 & 4296 & 4853 & \\
\hline S Rosa & 4000 & 4742 & & 2755 & 1916 & 1973 & 2031 & 2524 & 3056 & \\
\hline Santiago & 3842 & 2720 & & 3479 & 4081 & 4128 & 4276 & 3968 & 4304 & \\
\hline Itapua & 4782 & 5357 & & 6393 & 2591 & 2179 & 2106 & 3276 & 3789 & \\
\hline Candelária & 2596 & 2863 & & 3154 & 1503 & 1441 & 1639 & 2031 & 2409 & \\
\hline S Cosme & 1573 & 2120 & & 1236 & 1236 & 1209 & 1094 & 1449 & 1632 & \\
\hline S Ana & 2225 & 3600 & 5600 & 3716 & 4397 & 4533 & 4505 & 4778 & 5040 & 5191 \\
\hline Loreto & 4060 & 6113 & 7000 & 6077 & 1756 & 2246 & 2422 & 3276 & 4023 & \\
\hline S I Mini & & 3138 & 4300 & 3959 & 1849 & 1933 & 2076 & 2520 & 2773 & 4135 \\
\hline Corpus & 2080 & 3584 & & 4108 & 2667 & 2808 & 2922 & 3976 & 4773 & 4528 \\
\hline Trinidad & & 3140 & 3200 & 3598 & 2149 & 2268 & 2047 & 2629 & 2680 & \\
\hline Jesus & 1018 & 1947 & 2400 & 2241 & 1962 & 1836 & 1850 & 1899 & 2074 & \\
\hline S Carlos & 5355 & 3065 & & 3369 & 1239 & 1140 & 1273 & 1663 & 2024 & \\
\hline S Jose & 2594 & 3274 & & 3605 & 1338 & 1390 & 1411 & 2019 & 2310 & \\
\hline Aposteles & 3536 & 4140 & & 5207 & 1341 & 1494 & 1582 & 2118 & 2522 & \\
\hline Concepcion & 5653 & 4894 & & 5881 & 1669 & 1944 & 2369 & 2136 & 2912 & \\
\hline Martires & 2124 & 3343 & & 3665 & 2777 & 2829 & 2839 & 3112 & 3217 & \\
\hline La Mayor & 2869 & 3490 & 3900 & 3585 & 711 & 819 & 894 & 2128 & 2870 & \\
\hline S Javier & 4117 & 3409 & & 3663 & 1710 & 1789 & 1894 & 1968 & 1898 & \\
\hline S Nicolas & 4090 & 6667 & 7700 & & 1772 & 2194 & 2279 & 4255 & 416 & \\
\hline S Luis & 3354 & 5045 & & & 1978 & 2308 & 2432 & 3037 & 3828 & \\
\hline S Lorenzo & 4427 & 5224 & 6400 & 6099 & 974 & 1173 & 1311 & 1729 & 4459 & \\
\hline S Miguel & 2197 & 3972 & & & 4741 & 4740 & 4974 & 6635 & 1035 & \\
\hline S Juan & & 4629 & 4500 & & 4949 & 2171 & 2525 & 3221 & 3347 & \\
\hline Stos Ang. & & 4052 & & 4923 & 5163 & 5228 & 5199 & & 2531 & \\
\hline San Tome & 3416 & 2949 & & 3494 & 1699 & 1892 & 2063 & 2917 & 3042 & \\
\hline S Borja & & 2906 & & & 3244 & 3291 & 3430 & 3435 & 1668 & \\
\hline La Cruz & 3851 & 3615 & & & 2167 & 2163 & 2314 & 2518 & 2982 & \\
\hline Yapeyu & & 4360 & & & 5713 & 5687 & 5748 & 6518 & 7597 & \\
\hline
\end{tabular}

Fontes: As mesmas da Tabela 1. 
Missões nas fronteiras da América Espanhola: análise comparativa

\begin{tabular}{|c|c|c|c|c|c|c|c|c|c|c|}
\hline Missão & 1764 & 1767 & 1768 & 1772 & 1777 & 1784 & 1785 & 1796 & 1801 & 1802 \\
\hline Guasu & 3139 & 2100 & & 1655 & & 800 & 867 & 864 & 700 & 891 \\
\hline $\mathrm{LaFe}$ & 4716 & 3300 & 4300 & 2294 & & 800 & 1062 & 1144 & 1000 & 1113 \\
\hline S Rosa & 2031 & 2400 & 2522 & 2265 & & 1200 & 1264 & 1013 & 1200 & 1193 \\
\hline Santiago & 2712 & 3600 & & & & 2700 & 1215 & 1097 & 1262 & 1322 \\
\hline Itapua & 4308 & 4600 & 4679 & & & 2800 & 2889 & 2095 & 2131 & 1789 \\
\hline Candelária & 2817 & 3600 & 3687 & & & 1700 & 1748 & 1356 & 1200 & 1334 \\
\hline S Cosme & 2206 & 3300 & 3446 & & & 1200 & 1111 & 1038 & 800 & 850 \\
\hline S Ana & 4001 & 4400 & 4497 & 3077 & & 1700 & 1747 & 2471 & 1293 & 1464 \\
\hline Loreto & 4937 & 3200 & 2912 & 2492 & & 1300 & 1457 & 1095 & 1000 & 1046 \\
\hline S I Mini & 3074 & 3100 & & 3738 & & 600 & 798 & & 700 & 921 \\
\hline Corpus & 4280 & 4000 & 5093 & 4887 & 4121 & 2600 & 2574 & & 2300 & 2443 \\
\hline Trinidad & 2946 & 2600 & & 1477 & & 1100 & 1097 & 1017 & 877 & 851 \\
\hline Jesus & 2301 & 2900 & & 2392 & & 1200 & 1302 & 1185 & 800 & 700 \\
\hline S Carlos & & & & & & 1200 & & & 1013 & 1010 \\
\hline S Jose & & & & & & & & & 865 & 803 \\
\hline Aposteles & & & & & & & & & 1914 & 1058 \\
\hline Concepcion & & & & & & & & & 1127 & 975 \\
\hline Martires & & & 1882 & & & & & & 708 & 605 \\
\hline La Mayor & & & 3084 & & & & & 1383 & 559 & 573 \\
\hline S Javier & & & & & & 1379 & & & 959 & 1036 \\
\hline S Nicolas & & & 4194 & & & & & & 2406 & \\
\hline S Luis & & & 3510 & & & & & & 2350 & \\
\hline S Lorenzo & & & & & & & & & 1037 & \\
\hline S Miguel & & & 3525 & & & 1773 & & & 1664 & \\
\hline S Juan & & & 4106 & & & 2388 & & & 1600 & \\
\hline Stos Ang & & & 2687 & & & 1986 & & & 1092 & \\
\hline San Tome & & & & & & & & & & 1835 \\
\hline San Borja & & & 2761 & & & & & & 1300 & \\
\hline La Cruz & & & 3523 & & & & & & & 3458 \\
\hline Yapeyu & & & & & & & & & & 4669 \\
\hline
\end{tabular}

Fontes: As mesmas da Tabela 1. 


\begin{tabular}{|l|r|r|r|}
\hline \multicolumn{1}{|c|}{ Missão } & 1814 & 1822 & 1827 \\
\hline San Nicolas & 1545 & 250 & 404 \\
\hline San Luis & 1412 & 200 & 446 \\
\hline San Lorenzo & 434 & 250 & 258 \\
\hline San Miguel & 706 & 660 & 271 \\
\hline San Juan & 554 & 300 & 212 \\
\hline Santos Angeles & 320 & 350 & 103 \\
\hline San Borja & 1424 & 400 & 404 \\
\hline
\end{tabular}

Fontes: As mesmas da Tabela 1.

\section{Tabela 3}

Construção de La Purisima Mission, 1788-1812

\begin{tabular}{|c|c|c|}
\hline Ano & Edificio & Dimensões \\
\hline \multirow[t]{4}{*}{1789} & Igreja & $60.5^{\prime} \times 16.5^{\prime}$ \\
\hline & Sacristia & $13.8^{\prime} \times 16.5^{\prime}$ \\
\hline & Celeiro & $88^{\prime} \times 16.5^{\prime}$ \\
\hline & Cozinha & $13.8^{\prime} \times 16.5^{\prime}$ \\
\hline 1790 & Sete aposentos & $132^{\prime} \times 16.5^{\prime}$ \\
\hline \multirow[t]{2}{*}{1791} & Celeiro & $85.3^{\prime} \times 16.5^{\prime}$ \\
\hline & Três edifícios exteriores ao complexo & Não existente \\
\hline 1792 & Alargamento da igreja & $88^{\prime} \times 16.5^{\prime}$ \\
\hline 1793 & Ala & $173.3^{\prime} \times 16.5^{\prime}$ \\
\hline \multirow[t]{6}{*}{1794} & Quartel de soldados & $38.5^{\prime} \times 16.5^{\prime}$ \\
\hline & Armazém & Not given \\
\hline & Aposentos para visitantes & $22 \times 16.5^{\prime}$ \\
\hline & Aposentos do capataz & $33^{\prime} \times 16.5^{\prime}$ \\
\hline & Carpintaria & $22^{\prime} \times 16.5^{\prime}$ \\
\hline & Armazém para equipamento cavalaria & Não existente \\
\hline \multirow[t]{2}{*}{1795} & Celeiro & $85.5^{\prime} \times 19.3^{\prime}$ \\
\hline & Escritório & $33^{\prime} \times 19.3^{\prime}$ \\
\hline 1796 & Três armazéns & Não existente \\
\hline 1797 & Nova residência dos missionários & Não existente \\
\hline 1798 & Quartel novo & Não existente \\
\hline $1798-1802$ & Igreja nova & Não existente \\
\hline \multirow[t]{2}{*}{1799} & Aposento & $27.5^{\prime} \times 19.3^{\prime}$ \\
\hline & Aposento & $27.5^{\prime} \times 19.3^{\prime}$ \\
\hline 1800 & Ala & $192.5^{\prime} \times 19.3^{\prime}$ \\
\hline 1804 & Quartel novo & $110^{\prime} \times 19.3 ?^{\prime}$ \\
\hline 1812 & Terremoto destrói 100 casas índias de adobe & \\
\hline
\end{tabular}

Fonte: Annual Reports, Archivo General de la Nacion, Mexico, D. F.; Engelhardt, Zephyrin, O. F. M. Mission La Concepcion Purisima de Maria Santisima. Santa Barbara, 1932. 


\section{Figura 1}

Poblacion de las misiones jesuíticas de Paraguay, 1647-1801

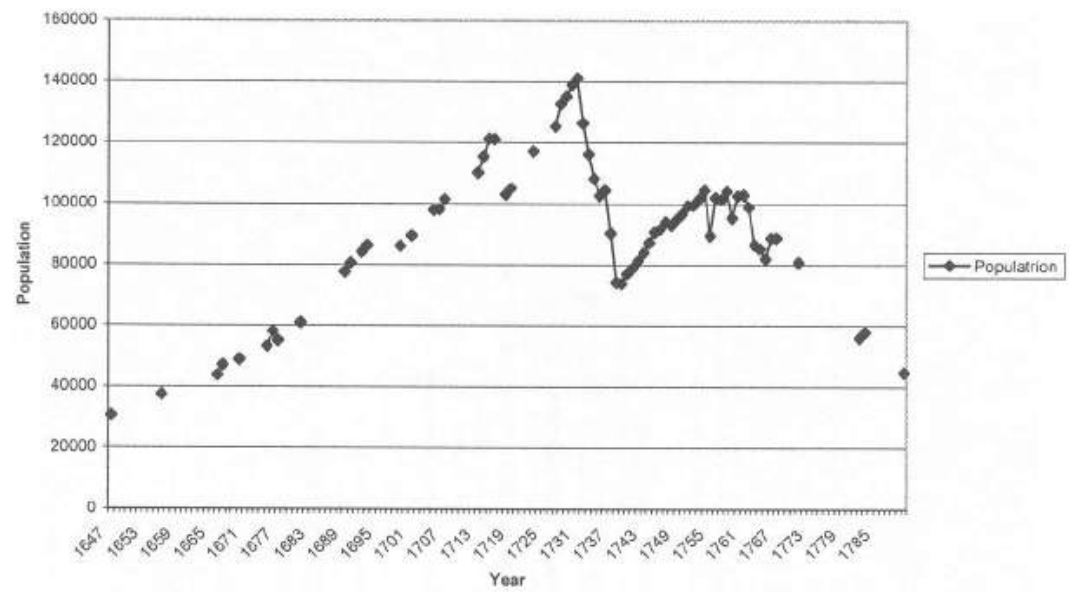

Figura 2

Bautismos I entierros registrados en la misions de Santa Gertrudis, 1751-1812

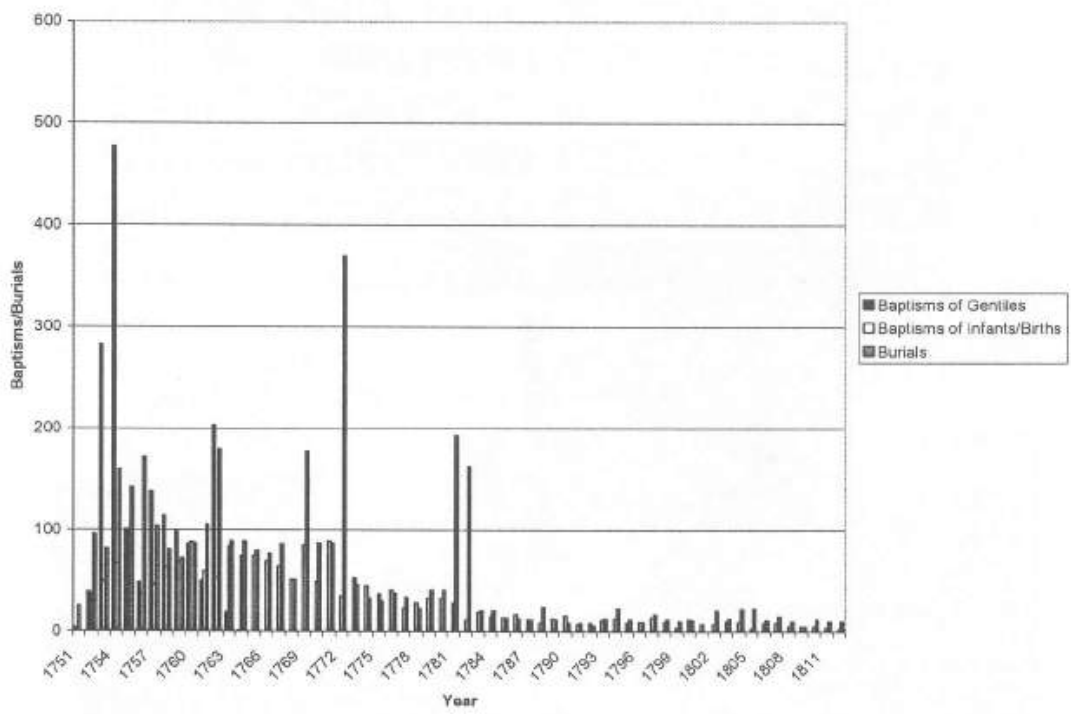


Figura 3

População dos Sete Povos, 1641-1827

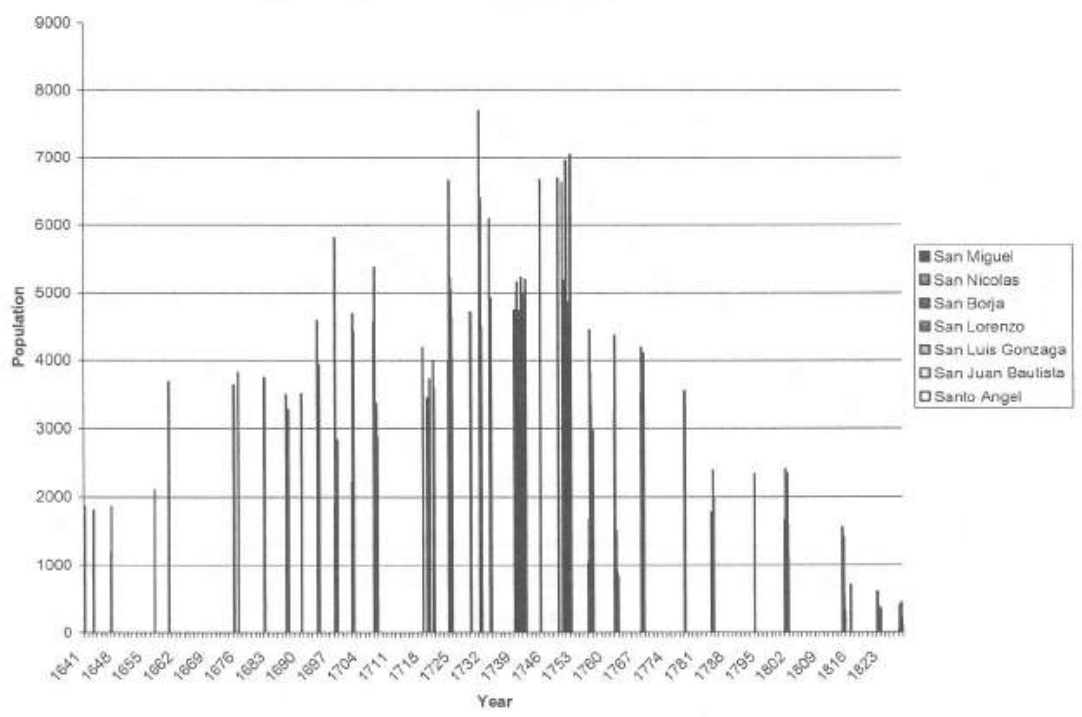




\section{Figura 4}

Maspa Hecho c. 1756 de la reducion de San Miguel

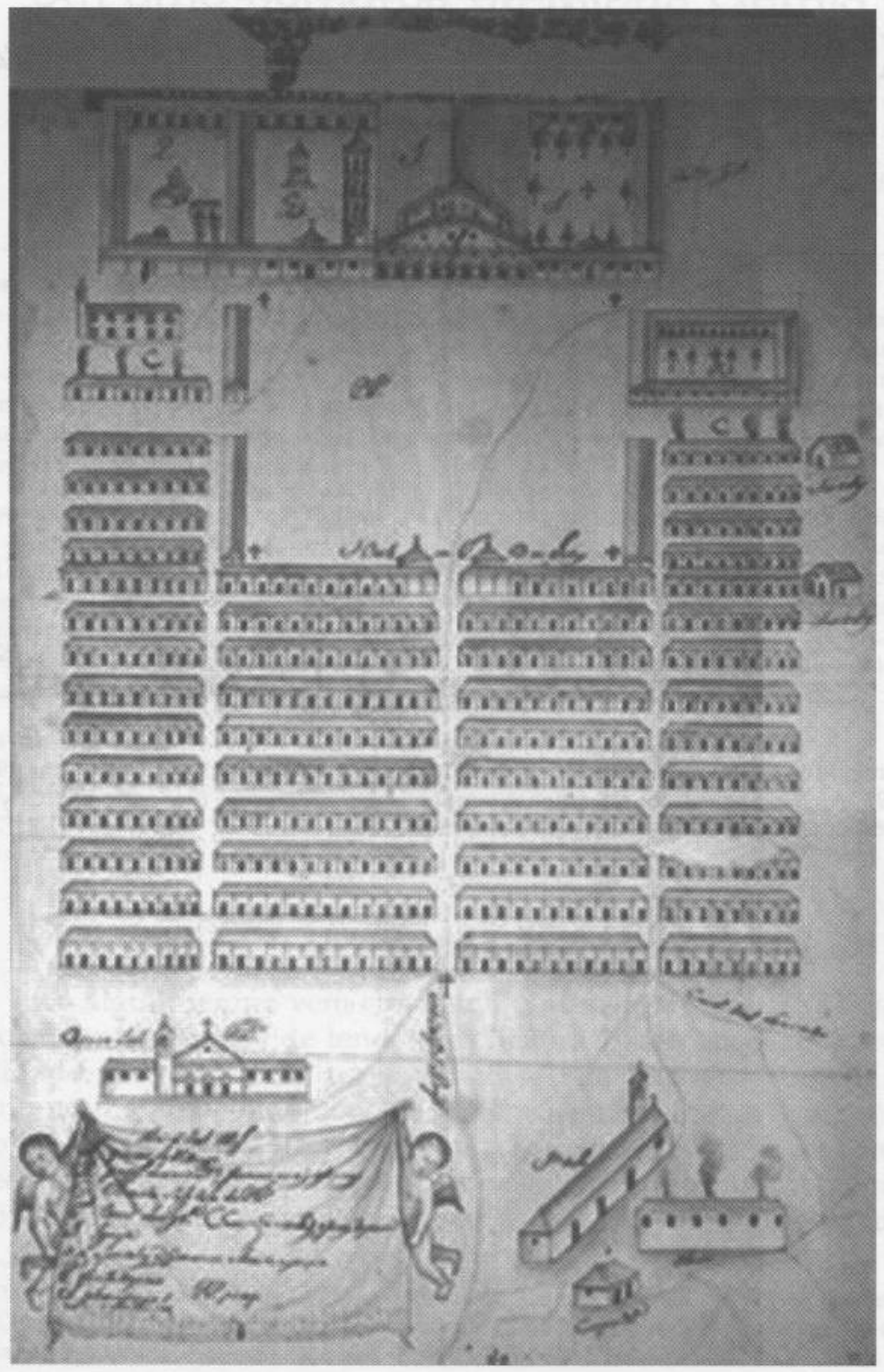


Figura 5

Mapa de los edificios del primer sitio de la mission de La Purisima

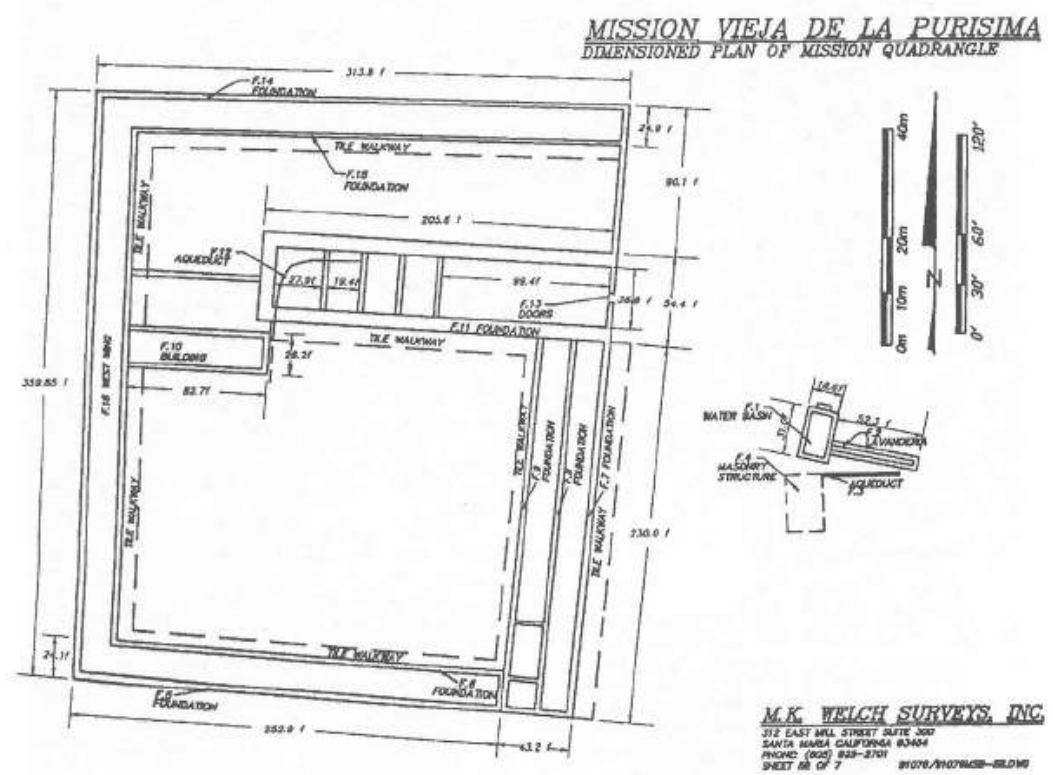

Fonte: Julia Costello, "Mission Vieja de la Purisima CA-SBA-521H: Report on the 19911992 Archaeological Investigations", unpublished report on file with the City of Lompoc Community Development Department, 1993. 